\title{
Conhecimento de enfermeiras acerca do papiloma vírus humano e câncer uterino
}

\author{
Knowledge of nursing professionals about human papillomavirus and uterine cancer
}

Conocimiento de las enfermeras sobre el virus del papiloma humano y el cáncer uterino

Edinilza da Silva Machado Medeiros ${ }^{1}$, Jacqueline Andréia Bernardes Leão-Cordeiro², Vera Aparecida Saddi ${ }^{3}$, Cesar Augusto Sam Tiago Vilanova-Costa ${ }^{4}$, Antonio Márcio Teodoro Cordeiro Silva ${ }^{3 *}$.

\section{RESUMO}

Objetivo: Investigar o conhecimento de enfermeiras sobre a vacina contra o papiloma vírus humano, a infecção por esse vírus e o câncer de colo uterino e a associação desse conhecimento com o tempo e instituição de formação, participação em educação permanente e carga horária de trabalho. Métodos: Pesquisa transversal, quantitativa, realizada com 33 enfermeiras, utilizando-se de um questionário. Analisaram-se os dados por meio de estatística descritiva e teste de fisher, $p$ significativo inferior a 0,05 . 0 estudo foi aprovado por Comitê de Ética em Pesquisa. Resultados: As enfermeiras tinham média de idade de 30,6 anos. $51,5 \%$ tinham tempo de formação de até cinco anos, $70,7 \%$ com pós-graduação lato sensu, prevalecendo a pós-graduação em saúde pública. Conheciam o papel do vírus na gênese do câncer cervical e das verrugas genitais. A associação entre esse conhecimento com o tempo e instituição de formação, participação em educação permanente, bem como carga horária de trabalho semanal, foi significativa a questões restritas. Conclusão: Conclui-se que as enfermeiras possuem conhecimentos sobre o papiloma vírus e câncer cervical, mas ainda necessitam de aprimoramento eficazes.

Palavras Chave: Conhecimento, Enfermagem, Infecções por papillomavirus.

\begin{abstract}
Objective: Investigate the knowledge of nurses about the human papilloma virus vaccine, the virus infection and cervical cancer and the association of this knowledge with the time and institution of training, participation in continuing education and workload. Methods: Cross-sectional, quantitative research with 33 nurses, using questionnaire. Data were analyzed using descriptive statistics and fisher test, $p$ was considered significant when less than 0.05 . The study was approved by a Research Ethics Committee. Results: The nurses had a mean age of 30.6 years. $51.5 \%$ had a training time of up to five years and $70.7 \%$ have lato sensu postgraduation. They knew the role of the virus in the genesis of cervical cancer and genital warts. The association between this knowledge over time and training institution, participation in continuing education, as well as weekly workload, was significant to restricted issues. Conclusions: Insummary, nurses show to have knowledge about papilloma virus and cervical cancer, but still need effective enhancement on topic.
\end{abstract}

Key words: Knowledge, Nursing, Papillomavirus infections.

1 Universidade Federal do Oeste da Bahia (UFOB), Barreiras - Bahia.

2 Universidade Federal do Goiás (UFG), Goiânia - Goiás.

${ }^{3}$ Pontifícia Universidade Católica de Goiás (PUC-Goiás), Goiânia - Goiás. *E-mail: marciocmed@gmail.com

${ }^{4}$ Associação de Combate ao Câncer em Goiás (ACCG), Goiânia - Goiás. 


\section{RESUMEN}

Objetivo: Investigar el conocimiento de las enfermeras sobre la vacuna contra el virus del papiloma humano, la infección con el virus del papiloma humano y el cáncer cervical, y la asociación de este conocimiento con el tiempo y la institución de capacitación, participación en educación continua y carga de trabajo. Métodos: Investigación cuantitativa transversal, realizada con 33 enfermeras, utilizando un cuestionario. Los datos fueron analizados por estadística descriptiva y prueba de pesca, $p$ significativo menor que 0.05. El estudio fue aprobado por el Comité de Ética en Investigación. Resultados: Las enfermeras tenía una edad media de 30,6 años. El 51.5\% tenía un tiempo de capacitación de hasta cinco años, el $70.7 \%$ tenía un título de posgrado lato sensu, prevaleciendo un posgrado en salud pública. Conocían el papel del virus en la génesis del cáncer cervical y las verrugas genitales. La asociación entre este conocimiento con el tiempo y la institución de formación, la participación en la educación continua, así como la carga de trabajo semanal, fue importante para los problemas restringidos. Conclusión: Se concluye que las enfermeras tienen conocimiento sobre el virus del papiloma y el cáncer cervical, pero aún necesitan una mejora efectiva.

Palabras clave: Conocimiento, Enfermería, Infecciones por papillomavirus.

\section{INTRODUÇÃO}

O papiloma vírus humano (HPV) é um agente infeccioso de distribuição universal que possui elevada associação com o câncer de colo de útero. Possui tropismo tanto por tecido cutâneo quanto mucoso, sendo classificado, de acordo com o poder oncogênico, em baixo e alto riscos (NOVAES LCG, 2002).

Embora exista um rigoroso programa de controle para o câncer de colo de útero, essa doença é tida como problema de saúde pública nos países em desenvolvimento (CARVALHO MDC, 2008). A efetividade desse programa depende da qualidade e integralidade dos serviços, com seguimento dos casos diagnosticados com lesões precursoras. Esse controle se dá por meio do exame de Papanicolau bem como por meio da vacina profilática, os quais possibilitam a redução da incidência da infecção pelo HPV, das lesões clínicas e subclínicas e consequentemente do câncer de colo de útero (BRASIL, 2014).

Elevadas taxas de morbimortalidade pelo câncer de colo de útero podem estar relacionadas a problemas no desempenho das ações de prevenção e controle da doença. A enfermeira desempenha papel fundamental para o controle dessa enfermidade, uma vez que pode contribuir por meio de suas ações com orientações, manejo clínico e encaminhamento adequados. Esse profissional deve compreender a subjetividade de cada indivíduo além de exercer uma prática assistencial pautada na humanização do cuidado, estimulo à autonomia e empoderamento da condição de saúde, de cada sujeito, em sua integralidade (FRACOLLI FA e CASTRO DFA, 2012). Além disso, a realização do exame de Papanicolau, no âmbito da equipe de enfermagem, é um procedimento privativo da enfermeira (COFEN, 2011).

Sendo assim, em função da importância da enfermeira para o controle do câncer de colo de útero é que se justifica esta pesquisa que teve como objetivo investigar o conhecimento de enfermeiras sobre a vacina contra o papiloma vírus humano, a infecção por esse vírus e o câncer de colo uterino e a associação desse conhecimento com o tempo e instituição de formação, participação em educação permanente e carga horária de trabalho.

\section{MÉTODOS}

Estudo transversal, de caráter descritivo, com abordagem quantitativa, realizado na Atenção Básica de um Município do oeste da Bahia, com 33 enfermeiras. Os critérios de inclusão utilizados foram: as enfermeiras deveriam atuar na rede assistencial de Atenção Básica escolhida e realizar a coleta do exame de Papanicolau. Para coleta dos dados, foi utilizado como instrumento um questionário, elaborado pelos pesquisadores, que continha questões para caracterização das participantes da pesquisa e questões que 
buscavam avaliar o conhecimento sobre a infecção pelo HPV; o conhecimento sobre câncer de colo uterino e a vacina anti-HPV.

O instrumento de coleta foi previamente validado por aplicações-teste, no intuito de verificar se os itens contidos conseguiam medir o que foi proposto. Avaliaram o instrumento 04 enfermeiras, que contemplaram os seguintes critérios de seleção: possuir graduação em enfermagem, especialização e atuação na área de saúde pública, e no ensino superior em enfermagem. Essas profissionais avaliaram a pertinência e a adequação do instrumento, quanto à aparência e ao conteúdo, item por item. Poderiam julgar os itens como adequados ou inadequados e sugerirem modificações e ou adaptações. Ao final o instrumento foi finalizado tendo por base as sugestões de modificação e adaptação de alguns itens.

Os dados foram analisados por meio de estatística descritiva dispondo em média, frequência relativa e absoluta. Adicionalmente, foi aplicado teste de fisher, com valor $p$ significativo inferior a 0,05.

Este estudo foi aprovado pelo Comitê de Ética em Pesquisa da Pontifícia Universidade Católica de Goiás, parecer número 1.128.677/2015, e respeitou as exigências formais contidas nas normas nacionais e internacionais regulamentadoras de pesquisas envolvendo seres humanos.

\section{RESULTADOS}

Participaram do estudo 33 enfermeiras, com média de idade de $30,6( \pm 7,3)$ anos, variações de 23 e 51 anos. Dessas participantes, 57,6\%(19) eram solteiras, 51,5\%(17) tinham tempo de formação de até cinco anos, $81,8 \%(27)$ provenientes de instituições particulares, 70,7\%(23) com pós-graduação lato sensu, prevalecendo a pós-graduação em saúde pública. Não foi evidenciada profissional com pós-graduação no nível stricto sensu. Quanto a caracterização do trabalho, foi possível evidenciar que $90,9 \%(30)$ atuavam no turno manhã/tarde, com uma carga horária de 40 horas semanais dedicadas à Atenção Básica, e 39,4\%(13) possuíam outro vínculo empregatício, sendo a área hospitalar a mais frequente. Verificou-se que $84,8 \%(28)$ dessas profissionais participavam de educação permanente e que $54,5 \%(18)$ receberam treinamento para a realização da coleta do exame de Papanicolau.

Quanto aos conhecimentos gerais acerca do HPV todas as enfermeiras já tinham ouvido falar sobre o vírus (Tabela 1). Consideravam a infecção comum e na maioria das vezes assintomática mais de $70 \%$ (24/26) dessas profissionais. Todas reconheciam o HPV como uma infecção sexualmente transmissível, mas muitas desconheciam outras formas de contrair o vírus. Mais da metade acreditava que o uso do preservativo reduzia totalmente a contaminação pelo vírus e que o exame de Papanicolau era um método diagnóstico para o HPV. A maioria das enfermeiras sabiam que o HPV podia atingir ambos os sexos e citaram as mulheres sexualmente ativas como as mais vulneráveis à infecção. Entendiam o papel do HPV na gênese do câncer cervical e das verrugas genitais, mas ficaram em dúvida quanto à relação desse vírus com outros tipos de cânceres.

Em relação às possíveis associações entre o conhecimento sobre a infecção pelo HPV, com o tempo de formação, participação em educação permanente, instituição de formação e a carga horária semanal total de trabalho, foi observado que as enfermeiras com tempo de formação entre 2 e 5 anos sabiam que a incidência da infecção pelo HPV era maior entre mulheres sexualmente ativas dos 20 aos 30 anos de idade, enquanto as demais ficaram confusas $(p=0,03)$. Em contrapartida, todas as enfermeiras com menos de 2 anos de formação não sabiam que, uma vez contraída a infecção, a pessoa será sempre portadora do vírus, ao passo que mais da metade com formação há mais de 2 anos possuía esse conhecimento $(p=0,01)$.

As enfermeiras que participavam de educação permanente não tinham certeza se o HPV podia ser transmitido via perinatal, ao passo que todas que não participavam de educação permanente sabiam dessa via de transmissão $(p=0,002)$.

As enfermeiras que participavam de educação permanente também ficaram confusas se a infecção pelo HPV possuía cura, ao contrário das que não participavam $(p=0,008)$. Não houve relação entre a instituição de formação e a carga horária semanal de trabalho com o conhecimento sobre a infecção pelo HPV. 
Tabela 1 - Conhecimentos gerais das enfermeiras acerca do papiloma vírus humano. Barreiras, Bahia, Brasil, 2016. ( $\mathrm{N}=33)$

\begin{tabular}{lccc}
\hline & $\mathbf{n}(\%)$ & $\mathbf{n}(\%)$ & $\mathbf{n}(\%)$ \\
\cline { 2 - 4 } Variáveis & $\mathbf{S i m}$ & $\mathbf{N a ̃ o}$ & $\mathbf{N R}^{*}$ \\
\hline Sobre o vírus & & & - \\
\hline Já ouviu falar & $33(100,0)$ & - & - \\
Infecção comum & $24(72,7)$ & $8(24,2)$ & $1(3,0)$ \\
Tem cura & $17(51,5)$ & $15(45,4)$ & $1(3,0)$ \\
Infecta apenas homens & $1(3,0)$ & - & - \\
Infecta apenas mulheres & $4(12,1)$ & - & - \\
Infecta homens/mulheres & $28(84,8)$ & - & - \\
Incidência > em mulheres sexualmente ativas & $28(84,8)$ & $3(9,1)$ & $2(6,1)$ \\
Prevenível 100\% pelo uso de condom & $17(51,5)$ & $15(45,4)$ & $1(3,0)$ \\
Diagnosticado pelo exame de Papanicolau & $22(66,7)$ & $10(30,3)$ & $1(3,0)$ \\
\hline Modo de transmissão & & & \\
\hline Beijo & $6(18,2)$ & $27(81,8)$ & - \\
Fluidos corporais & $18(54,5)$ & $15(45,5)$ & - \\
Água & - & $33(100,0)$ & - \\
Vertical & $18(54,4)$ & $11(33,3)$ & $4(12,1)$ \\
Sexual & $33(100,0)$ & - & - \\
\hline Sobre a infeção & & & - \\
\hline Sintomática & $7(21,2)$ & - & - \\
Assintomática & $26(78,8)$ & - & $2(6,1)$ \\
Homens são portadores sãos & $25(75,0)$ & $6(18,2)$ & $2(6,1)$ \\
Homens desenvolvem apena verrugas genitais & $9(27,2)$ & $22(66,7)$ & \\
\hline Associação do vírus & & & $1(3,0)$ \\
\hline Verrugas genitais & $30(90,9)$ & $2(6,1)$ & - \\
Câncer cervical & $30(90,9)$ & $3(9,1)$ & $1(3,0)$ \\
Câncer de reto & $21(63,6)$ & $11(33,3)$ & $2(6,1)$ \\
Câncer vaginal & $24(72,7)$ & $7(21,2)$ & $1(3,0)$ \\
Câncer de orofaringe & $16(48,5)$ & $16(48,5)$ & $1(3,0)$ \\
Câncer de pênis & $13(39,4)$ & $19(57,6)$ & $3(9,1)$ \\
Câncer de vulva & $15(45,4)$ & $15(45,4)$ &
\end{tabular}

Legenda: *não respondeu.

Fonte: Medeiros ESM, et al., 2020.

Quanto ao conhecimento relativo ao câncer de colo de útero foi possível perceber que muitas profissionais desconheciam a associação de cofatores para o desenvolvimento dessa doença (Tabela 2). Ao passo que $30,3 \%(10)$ acreditavam que infecção bacteriana era fator de risco. Relativo às manifestações clínicas, mais da metade das enfermeiras citaram o sangramento vaginal entre as menstruações, a presença de corrimento sanguinolento e a dor pélvica.

No que refere aos conhecimentos sobre a vacina anti-HPV, a maior parte da amostra, 97,0\%(32), já tinha ouvido falar da vacina, e 90,9\%(30) entendiam que a imunização é indicada para indivíduos que não tiveram contato com o vírus. Mais da metade, 51,5\%(17), defendia que quem pode utilizar a vacina eram apenas as mulheres, mas $36,4 \%(12)$ recomendaram a vacina quadrivalente para meninas e meninos, entre os 9 e 26 anos de idade. Do total, $66,7 \%(22)$ acreditavam que a vacina bivalente é recomendada para mulheres a partir dos 10 anos de idade. A maioria, 81,8(27), reconheceu a necessidade de realização do exame de Papanicolau anualmente, mesmo entre aquelas mulheres que foram vacinadas contra o HPV. Entretanto, 24,2\%(8) acreditavam que quem fez uso dessa vacina está livre de contrair esse vírus (Tabela 2).

Ao buscar associação entre o conhecimento sobre o câncer de colo de útero com o tempo de formação, participação em educação permanente, instituição de formação e a carga horária semanal total, foi possível observar que as enfermeiras, com tempo de formação de até 5 anos, sabiam que febre e dor de cabeça não são sintomas do câncer de colo de útero enquanto aquelas com tempo de formação maior que 5 anos ficaram em dúvida $(p=0,02)$. 
As enfermeiras que não participavam de educação permanente afirmaram que infecção bacteriana não é causa de câncer de colo de útero, em contrapartida as que participavam não foram unânimes $(p=0,04)$. As profissionais que cursaram enfermagem em instituição particular foram mais precisas que as provenientes de instituições públicas ao afirmarem que febre e dor de cabeça não são sintomas do câncer de colo de útero $(p=0,004)$.

Todas as enfermeiras com carga horária de trabalho semanal de até 40 horas foram precisas ao afirmarem que ter múltiplos parceiros sexuais era fator de risco para o câncer de colo de útero, contrário àquelas com carga horária de serviço semanal de mais de 40 horas que ficaram confusas $(p=0,001)$. Um total de $80 \%(16)$ daquelas que trabalhavam até 40 horas semanais também afirmaram ser fator de risco para o câncer de colo de útero a relação sexual precoce, contrapondo com $53,8 \%(7)$ das que possuíam carga horária de trabalho maior $(p=0,04)$.

Não foi evidenciada associação entre o conhecimento sobre a vacina contra o HPV com o tempo de formação, participação em educação permanente, instituição de formação e a carga horária semanal total de trabalho.

Tabela 2 - Conhecimento das enfermeiras acerca do câncer de colo de útero e da vacina contra o papiloma vírus humano. Barreiras, Bahia, Brasil. $(\mathrm{N}=33)$

\begin{tabular}{|c|c|c|c|}
\hline \multirow[b]{2}{*}{ Variáveis } & n (\%) & n (\%) & n (\%) \\
\hline & Sim & Não & $\mathbf{N R}^{*}$ \\
\hline \multicolumn{4}{|l|}{ Cofatores para o câncer de colo de útero } \\
\hline Genética & $20(60,6)$ & $12(36,4)$ & $1(3,0)$ \\
\hline Alimentação & $1(3,0)$ & $31(93,9)$ & $1(3,0)$ \\
\hline Infecção bacteriana & $10(30,3)$ & $23(69,7)$ & - \\
\hline Múltiplos parceiros sexuais & $30(90,9)$ & $3(9,1)$ & - \\
\hline Início precoce da atividade sexual & $22(66,7)$ & $11(33,3)$ & - \\
\hline Uso de dispositivo intra-uterino & $6(18,2)$ & $27(81,8)$ & - \\
\hline Tabagismo & $18(54,5)$ & $14(42,4)$ & $1(3,0)$ \\
\hline Etilismo & $12(36,4)$ & $20(60,6)$ & $1(3,0)$ \\
\hline Uso prolongado de contraceptivo hormonal via oral & $12(36,4)$ & $21(63,6)$ & - \\
\hline Falta de higiene & $3(9,1)$ & $30(90,9)$ & - \\
\hline \multicolumn{4}{|l|}{ São sinais e sintomas do câncer de colo de útero } \\
\hline Dor após as relações sexuais & $16(48,5)$ & $17(51,5)$ & \\
\hline Sangramento entre as menstruações & $17(51,5)$ & $15(45,5)$ & $1(3,0)$ \\
\hline Corrimento sanguinolento & $19(57,6)$ & $13(39,4)$ & $1(3,0)$ \\
\hline Febre/dor de cabeça & $3(9,1)$ & $29(87,9)$ & $1(3,0)$ \\
\hline Dor pélvica & $20(60,6)$ & $13(39,4)$ & - \\
\hline \multicolumn{4}{|l|}{ Sobre o exame de Papanicolau } \\
\hline Exame de prevenção primária para rastreamento do câncer de colo de útero & $32(97,0)$ & & $1(3,0)$ \\
\hline Exame que detecta anormalidade celular na cérvice uterina & $29(87,9)$ & $3(9,1)$ & $1(3,0)$ \\
\hline \multicolumn{4}{|l|}{ Sobre a vacina contra o HPV } \\
\hline Já ouviu falar & $32(97,0)$ & $1(3,0)$ & - \\
\hline Indicada para quem não teve contato com o vírus & $30(90,9)$ & $3(9,1)$ & - \\
\hline Pode ser utilizada apenas por homens & $1(3,0)$ & - & - \\
\hline Pode ser utilizada apenas por mulheres & $17(51,5)$ & - & - \\
\hline Pode ser utilizada por homens e mulheres & $15(45,5)$ & - & - \\
\hline Indicada apenas para homens & -1 & . & - \\
\hline Indicada apenas pera mulheres & $23(69,7)$ & - & - \\
\hline Indicada para homens e para mulheres & $10(30,3)$ & 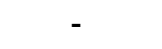 & - \\
\hline \multicolumn{4}{|l|}{ A quadrivalente é indicada par meninas e meninos entre } \\
\hline $09-26$ anos & $12(36,4)$ & $20(60,6)$ & $1(3,0)$ \\
\hline A bivalente é indicada para mulheres à partir dos 10 anos & $22(66,7)$ & $10(30,3)$ & $1(3,0)$ \\
\hline Mulheres vacinadas nã̃o precisam realizar o exame de Papanicolau & $27(81,8)$ & $6(18,2)$ & - \\
\hline Quem fez uso está livre de contrair o papiloma vírus & $8(24,2)$ & $25(75,8)$ & - \\
\hline
\end{tabular}

Legenda: *não respondeu.

Fonte: Medeiros ESM, et al., 2020. 


\section{DISCUSSÃO}

A presença feminina na enfermagem, embora a profissão esteja passando por transformações com a inserção dos homens, ainda tem prevalecido (RIBEIRO GKNA, et al., 2014). Dado corroborado neste estudo que evidenciou que todos os profissionais bacharéis em enfermagem, atuantes na Atenção Básica, eram do sexo feminino e pelo estudo de Martins $C$ et al. (2006) que ao realizar a caracterização, quanto ao sexo, dos profissionais de enfermagem verificaram que apenas $8 \%$ eram do sexo masculino. Principamente na enfermagem, a prevalência de mulheres é explicada em função das atribuições que foram dadas a esse grupo, em que o cuidado e a assistência são considerados como extensão das atividades femininas.

Neste estudo, foi evidenciado que a educação permanente para as enfermeiras não tinha periodicidade e era realizada por enfermeiras apoiadoras. Cada enfermeira apoiadora ficava responsável por quatro unidades de saúde. Elas atendiam às demandas das enfermeiras assistenciais por meio de solicitação e também por meio das queixas dos usuários à ouvidoria do Município. Em relação ao treinamento para a coleta do exame citológico, dado semelhante foi encontrado no estudo de Oliveira NC, et al. (2010), em que parte das enfermeiras também não eram qualificadas para a realização desse procedimento, o que pode suscitar dúvida referente à prática da coleta, análise e conduta desse exame por essas profissionais.

Observa-se a pouca valorização da preparação das enfermeiras para a coleta do exame preventivo de câncer de colo de útero (MARÇAL JA, 2013), e isso é uma questão relevante, pois são essas que realizam a coleta do exame de Papanicolau, a leitura do resultado e estipulam a conduta. Dessa forma, para a realização desse procedimento a enfermeira deverá estar dotada de conhecimentos, competências e habilidades que garantam rigor técnico-científico ao procedimento, atentando para a capacitação contínua necessária à sua realização (COFEN, 2011). Falhas nesse processo comprometem a qualidade das ações de saúde com repercussão direta na vida das pacientes e no sistema de saúde como um todo.

É perceptível que os estudos que buscam investigar o conhecimento relacionado à infecção pelo HPV, câncer de colo de útero e a vacina anti-HPV inserem principalmente estudantes de enfermagem (PANOBIANCO M, et al., 2013; ANDRADE TMF, et al., 2013; CIRILO CA, et al., 2010), e outras áreas da saúde (RASHWAN HH, et al., 2012). Essa condição impossibilitou a comparação dos resultados encontrados nesta pesquisa com o desempenho de outras enfermeiras.

No que tange aos conhecimentos sobre a infecção pelo HPV, todas as enfermeiras já tinham ouvido falar do vírus e o classificaram como uma infecção sexualmente transmissível. Dado esse corroborado por um estudo realizado com estudantes da área da saúde na Malásia (RASHWAN HH,et al., 2012). As ações de educação em saúde, desempenhadas na Atenção Básica pelas enfermeiras, são ferramentas essenciais para a orientação e capacitação dos indivíduos, especialmente os adolescentes, considerados como os mais vulneráveis para aquisição de infecção sexualmente transmissível.

Algumas formas de transmissão do vírus eram desconhecidas pelas enfermeiras, semelhante aos dados encontrados em outro estudo (ANDRADE TMF, et al., 2103), em que outras formas de propagação, que não a sexual, não era de conhecimento. A principal via de transmissão do vírus é a sexual, todavia existem outras vias de contaminação, como, por exemplo, a via perinatal e a transmissão por autoinoculação (DUNNE EF, et al., 2006). Na prática da enfermeira, o conhecimento relativo às infecções sexualmente transmissíveis e como se dá o contágio é primordial para a promoção de orientação adequada das formas de prevenção e controle, a fim de reduzir a incidência da infecção.

A maior parte das participantes acreditavam que a infecção pelo vírus era comum e na maioria das vezes assintomática e que o preservativo consistia em um método que oferecia 100,0\% de eficácia, similar a outro estudo (CIRILO CA, et al., 2010). A infecção pelo HPV é uma infecção sexualmente transmissível de elevada prevalência em todo o mundo, mas apenas alguns casos apresentam sintomatologia clínica, a maioria com regressão espontânea. Os casos em que se observa a persistência da infecção é que estão associados ao câncer de colo de útero.

O preservativo, mesmo que não ofereça $100 \%$ de eficácia, é um forte aliado para a redução da transmissão e infecção genital causada pelo HPV (VERA EG, et al., 2008). A falsa ideia de que o 
preservativo seja um método totalmente eficaz contra a transmissão do vírus pode contribuir para o aumento dos casos de contaminação.

Da mesma maneira que as enfermeiras desta pesquisa, em um estudo realizado com acadêmicos de medicina, os participantes elegeram o exame de Papanicolau como o principal método para a detecção precoce do câncer de colo de útero (GOMES CHR, et al., 2008). Neste estudo as profissionais acreditavam que esse exame consistia em método de prevenção primária capaz de detectar a presença do vírus papiloma na cérvice uterina. Entretanto, o exame de Papanicolau é classificado como um método de prevenção secundária (SANTOS FAPS, et al., 2011).

Como método de prevenção secundária o exame de Papaniculau irá possibilitar a detecção de alteração celular com potencial de malignidade, por meio da análise microscópica de células obtidas através da descamação da cérvice uterina. Essas células diagnosticadas antes de se tornarem malignas, ou em uma fase inicial do tumor, têm possibilidade de tratamento e cura favoráveis. Dessa maneira, o exame de Papanicolau é um método capaz de detectar alteração celular com potencial de malignidade e não a presença do HPV (MOTTA EV, et al., 2001). Nesse sentido, apesar de não detectar a presença do HVP o exame é capaz de diagnosticar as lesões a ele associadas, sendo indicado anualmente para mulheres prioritariamente na faixa etária dos 25 aos 64 anos de idade, que já iniciaram atividade sexual, e de três em três anos, caso os dois últimos exames consecutivos tenham sido normais (BRASIL, 2013).

Nesta pesquisa, as enfermeiras também acreditavam que qualquer pessoa era vulnerável a infecção pelo HPV e que a incidência era maior entre mulheres sexualmente ativas. Ainda que, tanto as mulheres quanto os homens possam contrair o vírus, a repercussão da infecção é maior na população feminina, devido a relação com o câncer de colo de útero (NOVAES LCG, 2002).

As enfermeiras sabiam que os homens são, na maioria das vezes, portadores assintomáticos do HPV, mas defendiam a ideia de que, no homem, o vírus causava apenas verrugas genitais. Além disso, algumas desconheciam a existência de casos de câncer, nessa população, associados ao vírus. Apesar de que, na maioria das vezes, no homem, a infecção pelo HPV tenha curso benigno e subclínico, as manifestações clínicas estão associadas às lesões condilomatosas, na região genital, cavidade oral e também neoplasia (GIULIANO AR, et al., 2008).

No que se refere à associação da infecção pelo HPV e o câncer de colo de útero, diferentemente do estudo de Andrade TMF, et al. (2013), grande parte das participantes referiram conhecer o papel do vírus na oncogênese cervical. Porém, desconheciam a relação com outros tipos de neoplasias. Aproximadamente $100,0 \%$ dos casos de câncer de colo de útero possuem associação com a infecção pelo HPV (NOVAES LCG, 2002). Mas, a infecção pelo HPV, em menor proporção, também está associado a outros cânceres (MOTTA EV, et al., 2001).

A quantidade de enfermeiras, que conheciam os fatores de risco para o câncer de colo de útero, foi bem maior do que a encontrada em estudo realizado com estudantes de enfermagem (CIRILO CA, et al., 2010). Isso indica que o conhecimento é diretamente proporcional ao nível de escolaridade. Entretanto, as enfermeiras deste estudo precisam de aprimoramento técnico-científico pois, equivocadamente, consideram infecção bacteriana como uma das causas do câncer cervical. O processo de carcinogênese cervical depende não apenas da presença do vírus HPV, mas do potencial de oncongenicidade desse vírus e também de fatores relacionados à imunidade do indivíduo, predisposição genética, coinfecção por alguma infecção sexualmente transmissível, tabagismo, uso de contraceptivo via oral, dentre outros (PINTO AP, et al., 2012). Embora relacionada a quadro de morbidade, a infecção bacteriana não é considerada cofator para o desenvolvimento do câncer de colo de útero.

No que tange as manifestações clínicas do câncer de colo uterino, contrapondo com o estudo de Panobianco M, et al. (2013), mais da metade das participantes conseguiram identificar os sintomas da doença. Os tumores cervicais são assintomáticos na fase inicial, mas com a progressão podem surgir as manifestações clínicas como sangramento fora do período menstrual, leucorreia intensa, dor pélvica, consequente comprometimento intestinal e urinário (BRASIL, 2013). O diagnóstico da doença deve ser 
realizado antes do surgimento desses sintomas, para assim aumentarem as chances de eficácia da terapêutica preconizada. Relativo à vacina anti-HPV, diferente do estudo de Andrade TMF, et al. (2013), a maior parte das enfermeiras possuíam conhecimento. Todavia, uma pequena parcela acreditava que quem fez uso da vacina anti-HPV estava livre de contrair o vírus. Ressalta-se que a vacina oferece proteção apenas contra quatro tipos virais de HPV, considerados de importância epidemiológica. $\mathrm{O}$ tipo bivalente protege contra os vírus 16 e 18, e o tipo quadrivalente protege contra os tipos $6,11,16$ e 18. Sendo assim, a vacina contra o HPV não substitue o restreamento das lesões precursoras de câncer de colo uterino, já que não oferece proteção contra todos os tipos virais do papiloma.

As vacinas profiláticas oferecem benefícios tanto para os indivíduos do sexo feminino quanto masculino antes da exposição ao vírus (NADAL LRM e NADAL SR, 2008). Mesmo que, na maioria das vezes, no homem, a infecção pelo HPV tenha curso benigno e subclínico (GIULIANO AR e SALMON D, 2008), as manifestações clínicas estão associadas às lesões condilomatosas, característica de "couve-flor", na região genital (GIULIANO AR, et al., 2008). Mas, o vírus está associado também às lesões na cavidade oral e muito raramente a algumas neoplasias. Portanto, o homem é considerado um grande transmissor e propagador do vírus, contribuindo para a prevalência elevada da infecção (FELLER LL, et al., 2009).

Considerou-se como limites, deste estudo, o desenho metodológico, uma vez que na pesquisa transversal não há seguimento dos participantes. Além disso, a amostra é considerada pequena, dificultando generalizações.

\section{CONCLUSÃO}

Ficou evidenciado, através deste trabalho, que as enfermeiras participantes do estudo possuem conhecimento sobre a vacina anti-HPV, infecção pelo HPV e câncer de colo uterino. Mas, é importante haver implementação de educação permanente que atenda a necessidade de saúde da comunidade locorregional. É esperado que esta pesquisa possa contribuir para a enfermagem uma vez que aponta o conhecimento das enfermeiras acerca de uma temática que faz parte do cotidiano dessas profissionais na Atenção Básica. Ademais, pode direcionar a implementação de políticas públicas de educação permanente para aprimorar o conhecimento dessas profissionais.

\section{REFERÊNCIAS}

1. ANDRADE TMF, et al. Knowledge of nursing students about human Papillomavirus infection and vaccination. DST - J bras Doenças Sex Transm. 2013; 25(2): 77-81.

2. BRASIL. Ministério da Saúde (BR). Instituto Nacional do Câncer. Estimativa 2014: Incidência do câncer no Brasil. Rio de Janeiro: INCA, 2014.

3. BRASIL. Ministério da Saúde (BR). Controle dos cânceres do colo do útero e da mama. Secretaria de Atenção à Saúde, Departamento de Atenção Básica. - 2. ed. - Brasília:Ministério da Saúde, 2013.

4. CARVALHO MDC. Comparação do desempenho entre a citopatologia-colposcopia e os achados da histopatologia nas lesões do colo uterino. Rev Bras Ginecol Obstet. 2008; 30(9): 480.

5. CONSELHO FEDERAL DE ENFERMAGEM. Resolução COFEN № 381/2011. Disponível em:http://www.cofen.gov.br/resoluo-cofen-n-3812011_7447.html. [citado 2016 jan 08].

6. CIRILO CA, et al. Nível do comportamento e conhecimento sobre o papilomavírus humano entre universitários do curso de Enfermagem. Rev Soc Bras Med Trop. 2010; 43(4): 362-366.

7. DUNNE EF, et al. Prevalence of HPV infection among men: a systematic review of the literature. J Infect Dis. 2006; 15(8): 1044-57.

8. FELLER LL, et al. Epithelial maturation and molecular biology of oral HPV. Infect Agent Cancer. 2009;4:16.

9. FRACOLLI FA, CASTRO DFA. Competência do Enfermeiro na Atenção Básica: em foco o processo de humanização do trabalho. O Mundo da Saúde. 2012; 36(3): 427-432.

10. GIULIANO AR, SALMON D. The case for a gender-neutral (universal) human papillomavirus vaccination policy in the United States: Point. Cancer Epidemiol Biomarkers Prev. 2008;17(4): 805-8.

11. GIULIANO AR, et al. The human papillomavirus infection in men study: human papillomavirus prevalence and type distribution among men residing in Brazil, Mexico and the United States. Cancer Epidemiology Biomarkers Prevention. 2008; 17(8): 2036-43. 
12. GOMES CHR, et al. Avaliação do Conhecimento sobre Detecção Precoce do Câncer dos Estudantes de Medicina de uma Universidade Pública. Rev bras cancerol. 2008; 54(1): 25-30.

13. MARÇAL JA. A prevenção do câncer de colo de útero realizada pelo Enfermeiro na Estratégia Saúde da Família: Revisão integrativa da literatura. REAS. 2013; 5(2): 474-489.

14. MARTINS C, et al. Perfil do enfermeiro e necessidades de desenvolvimento de competência profissional. Texto Contexto Enferm. 2006; 15(3): 472-8.

15. MOTTA EV, et al. Colpocitologia em ambulatório de ginecologia preventiva. Rev Assoc Med Bras. 2001; 47(4): 302-10.

16. NADAL LRM, NADAL SR. Indicações da vacina contra o Papilomavirus Humano. Rev Bras Coloproct. 2008; 28(1): 124-6.

17. NOVAES LCG. Biologia Molecular dos papilomavirus humanos e sua participação na carcinogênese. Rev saúde Dis Fed. 2002; 13(3/4): 29-36.

18. OLIVEIRA NC, et al. Desempenho de Enfermeiras na coleta de material cervicouterino para exame de Papanicolaou. Acta Paul Enferm. 2010; 23(3): 385-91.

19. PANOBIANCO M, et al. O conhecimento sobre o HPV entre adolescentes estudantes de graduação em Enfermagem. Texto Contexto Enferm. 2013; 22(1): 201-207.

20. PINTO AP, et al. Co-fatores do HPV na oncogênese cervical. Rev Assoc Med Bras. 2002; 48(1): 73-8.

21. RASHWAN HH, et al. Knowledge, attitude and practice of malaysian medical and pharmacy students towards human papillomavirus vaccination. APJCP. 2012; 13(5): 2279-2283.

22. RIBEIRO GKNA, et al. Profissionais de Enfermagem habilitados para o mercado de trabalho em Minas Gerais. REME. 2014; 18(1): 15-20.

23. SANTOS FAPS, et al. Exame Papanicolau: avaliação da qualidade do esfregaço cervical. Rev Rene. 2011; 12(3): 645-8.

24. VERA EG, et al. Efectividad del preservativo para prevenir el contagio de infecciones de trasmisión sexual. Ginecol Obstet Mex. 2008; 76(2): 88-96. 